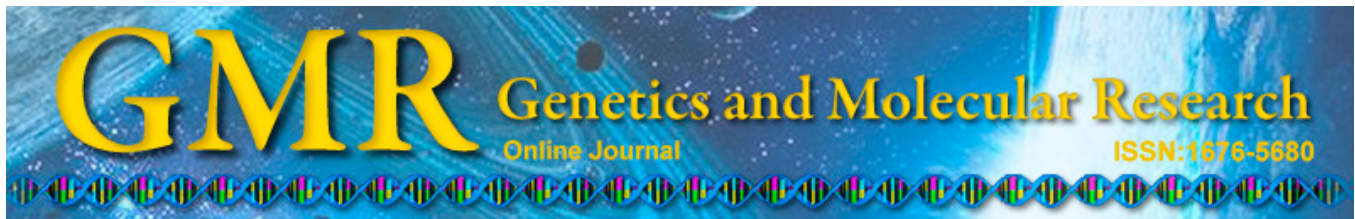

\title{
Phosphorylation of the GluN1 subunit in dorsal horn neurons by remifentanil: a mechanism for opioid-induced hyperalgesia
}

\author{
C. Zhang, S.S. Li, N. Zhao and C. Yu \\ Chongqing Key Laboratory for Oral Diseases and Biomedical Sciences, \\ The Affiliated Hospital of Stomatology, Chongqing Medical University, \\ Chongqing, China
}

Corresponding author: $\mathrm{C}$. Yu

E-mail: yucongab@sina.com

Genet. Mol. Res. 14 (1): 1846-1854 (2015)

Received October 15, 2014

Accepted January 28, 2015

Published March 13, 2015

DOI http://dx.doi.org/10.4238/2015.March.13.13

\begin{abstract}
Remifentanil (an ultra-short acting $\mu$-opioid receptor agonist) use has been associated with acute opioid tolerance and hyperalgesia. Previous electrophysiological studies have shown that remifentanil elicits rapid and prolonged upregulation of N-methylD-aspartate receptor (NMDAR) currents. However, the effect of remifentanil on the levels of the GluN1 subunit of the NMDAR in dorsal horn neurons (DHNs) has not been reported. We investigated the effect of remifentanil, along with ketamine (NMDAR antagonist) and naloxone ( $\mu$-opioid receptor antagonist), on GluN1 mRNA levels and the amount of phosphorylated GluN1 in primary cultures of embryonic rat DHNs. DHNs were isolated from 18-19-day rat embryos and treated with remifentanil or vehicle for $1 \mathrm{~h}$. GluN1 mRNA and protein levels, determined by real time reverse transcription polymerase chain reaction (RT-PCR) and Western blot, respectively, were significantly and persistently increased by remifentanil exposure compared with the control group $(\mathrm{P}<0.05)$. These results may partially account for the
\end{abstract}


mechanism of remifentanil-induced hyperalgesia. This increase was prevented by ketamine (NMDAR antagonist) and naloxone ( $\mu$-opioid receptors antagonist), thus providing a potential therapeutic mechanism for the prevention of opioid-induced hyperalgesia.

Key words: Remifentanil; Opioid-induced hyperalgesia; NMDA receptor; $\mu$-Opioid receptor

\section{INTRODUCTION}

Opioids are the most commonly used drugs for the treatment of moderate to severe surgical and chronic pain. However, opioid therapy intended to alleviate pain may make patients more sensitive to pain, and may even aggravate preexisting pain. This phenomenon is called opioid-induced hyperalgesia (OIH) (Li et al., 2001; Angst and Clark, 2006). OIH develops more rapidly and frequently after administration of short-acting opioids, such as remifentanil, compared with long-acting opioids (Derrode et al., 2003; Colvin and Fallon, 2010). It has been reported that intraoperatively administered remifentanil could lead to acute opioid tolerance or hyperalgesia manifested by increased postoperative pain and opioid consumption (Guignard et al., 2000; Hood et al., 2003). Since remifentanil is widely used by anesthesiologists, OIH is an important problem that should be resolved urgently.

Glutamate is the major excitatory neurotransmitter in pain signal transmission. Pain signals propagate through the spinal cord via glutamatergic transmission involving the N-methyl-D-aspartate receptor (NMDAR), a type of ionotropic glutamate receptor (Celerier et al., 1999; Hahnenkamp et al., 2004). There are seven NMDAR subunits encoded by the GRIN1, GRIN2A-2D, GRIN3A, and GRIN3B genes (with the GRINXX gene encoding the GluNXX subunit). Functional NMDARs are tetramers with two obligatory GluN1 glycinebinding subunits and two GluN2 or GluN3 glutamate-binding subunits (Furukawa et al., 2005; Paoletti and Neyton, 2007).

A number of studies have demonstrated that opioids enhance NMDAR function, especially remifentanil (Zhao and Joo, 2008; Gu et al., 2009). In a model of inflammatory and neuropathic pain, phosphorylation of GluN1 was found to be the major mechanism by which the activity of NMDARs is regulated (Du et al., 2003). Thus far, it is not clear whether this mechanism exists in $\mathrm{OIH}$ after exposure to remifentanil.

NMDARs are located postsynaptically and extrasynaptically in the membrane of DHNs (Nagy et al., 2004). Therefore, we chose primary cultures of embryonic rat DHNs as a model to study the mechanisms of remifentanil-induced acute opioid tolerance and hyperalgesia. NMDARs, which are composed of two obligatory GluN1 and two regulatory GluN2/3 subunits, play a key role in the induction of many forms of synaptic plasticity. Synaptic NMDAR number and subunit composition are not static, but changed dynamically in a cell-specific and synapse-specific manner during development and in response to neuronal activity or sensory experience (Lau and Zukin, 2007). Therefore, NMDAR expression and function are considered to be pivotal in the development of OIH. NMDAR function is rapidly enhanced during 4-8 $\mathrm{nM}$ remifentanil infusion (Zhao and Joo, 2008; Hang et al., 2011). Remifentanil application also increases the number of different NMDAR subunit combinations (Hahnenkamp et al., 2004).

Ketamine, a noncompetitive NMDAR antagonist, is a widely used general anesthetic 
because of its analgesic effects. Although ketamine acts on a variety of receptors, its analgesic effects stem mainly from its antagonism of NMDARs and prevention of central sensitization (Hirota and Lambert, 1996). One study has demonstrated the efficacy of NMDAR antagonists for preventing OIH (Minville et al., 2010). Furthermore, a number of investigations found that clinical doses of naloxone antagonize opioid effects, whereas ultra-low doses enhance the antinociceptive effects of morphine (Tsai et al., 2008; Yang et al., 2011).

In this study, we investigated the relationships among the GluN1 subunit, opioids, and $\mathrm{OIH}$ in search of an effective method to treat OIH. We specifically examined: 1) whether remifentanil leads to overexpression of phosphorylated GluN1 (p-GluN1) in spinal cord dorsal horn neurons (DHNs), 2) what the time course of the effect is, and 3) whether this effect is inhibited by ketamine or naloxone.

\section{MATERIAL AND METHODS}

\section{Cell culture}

All procedures were in accordance with the Institutional Animal Care and Use Committee at Chongqing Medical University. Pregnant female Wistar rats (Chongqing Medical University breeding facility) weighing between 150 and $250 \mathrm{~g}$ were used for all experiments.

Rats were sacrificed after sevoflurane anesthesia (Hengrui, China), the heads of 1819-day embryos were removed, and the whole spinal cord was dissected out and submerged in ice-cold Hank's Balanced Salt Solution (HBSS, Bioroc, China). The meninges were carefully stripped and the spinal cord was incised longitudinally along the midline. The lateral funiculus from both sides of the spinal cord was digested in HBSS containing $0.25 \%$ trypsin (Bioroc) at $37^{\circ} \mathrm{C}$ for $45 \mathrm{~min}$, and then washed with PBS (Bioroc) and homogenized. The cells were then suspended in Minimum Essential Medium (MEM, Gibco, Carlsbad, CA, USA) containing 10\% fetal bovine serum (FBS, Gibco), 10\% horse serum (Gibco) and $1 \mathrm{U} / \mathrm{mL}$ insulin (Invitrogen, Carlsbad, CA, USA). The dispersed cells were then plated on collagen (from rat tail)-coated dishes at a density of $2 \times 10^{4}$ cells $/ \mathrm{mL}$ and cultured in a $37^{\circ} \mathrm{C}$ incubator with $10 \% \mathrm{CO}_{2}$. After 6 days of incubation, the cells were cultured with MEM containing $10 \%$ horse serum, $1 \mathrm{U} / \mathrm{mL}$ insulin, and the mitotic inhibitors 5-fluoro-2'-deoxyuridine ( $15 \mu \mathrm{g} / \mathrm{mL}$, Sigma, St. Louis, MO, USA) and uridine ( $35 \mu \mathrm{g} / \mathrm{mL}$, Sigma) to inhibit non-neural cell proliferation. All cells used in experiments were cultured for at least 14-21 days to ensure the expression of NMDARs.

\section{Drugs}

Drugs were obtained as follows: remifentanil hydrochloride (batch number: 6120306, Ren Fu Co., China), ketamine hydrochloride (batch number: KH080601, Heng Rui Co., China), sevoflurane (batch number: 08100931, Heng Rui Co., China), glycine (batch number: 1259344, Novon Co., USA), and naloxone (batch number: 20110808, Xinhua Co., China).

Remifentanil (4 $\mathrm{nM})$ perfused onto DHNs caused a significant increase in peak NMDAR currents, as in a previous study (Zhao and Joo, 2008), so we used this concentration for all experiments. The vehicle of the pharmaceutical preparation of remifentanil contains $3 \mathrm{mM}$ glycine per $50 \mu \mathrm{M}$ remifentanil (Guntz et al., 2005). This concentration of glycine is unlikely to potentiate NMDAR function through direct activation, coactivation, or receptor 
trafficking (Nong et al., 2003). The extracellular solutions we used routinely contained $3 \mu \mathrm{M}$ glycine and did not enhance NMDAR function. Therefore, the remifentanil, other antagonists, and control perfusion solutions were adjusted to uniformly contain $3 \mu \mathrm{M}$ glycine for all experiments (Zhao and Joo, 2008).

\section{Experimental groups}

All cells were divided into 6 groups. In each group, drugs were applied to the cells for $1 \mathrm{~h}$, and the amount of p-GluN1 or GluN1 mRNA was measured by western blotting experiments or real-time reverse transcription polymerase chain reaction (RT-PCR), respectively, at $1,2,4$, and $24 \mathrm{~h}$ after drug washout.

The groups were defined as follows: Group C, control (saline with $3 \mu \mathrm{M}$ glycine); Group R, remifentanil (4 nM); Group RK, remifentanil (4 nM) + ketamine (100 $\mu \mathrm{M})$; Group $\mathrm{RN}$, remifentanil $(4 \mathrm{nM})+$ naloxone $(100 \mathrm{nM})$.

\section{Real-time RT-PCR}

Total RNA was extracted with TRIzol reagent (Invitrogen) according to the manufacturer protocol. The concentration and purity of total RNA were determined by a spectrophotometer (Eppendorf, Hamburg, Germany). Reverse transcription was performed using a first strand cDNA synthesis kit (FSK-100) (TOYOBO, Osaka, Japan). cDNA was stored at $-20^{\circ} \mathrm{C}$. PCR mixtures contained $2 \mu \mathrm{L}$ cDNA, $10 \mu \mathrm{L}$ PCR Premix $2 \mathrm{X}$, and $0.25 \mu \mathrm{M}$ forward and reverse primers, for a total volume of $20 \mu \mathrm{L}$. Reactions were started with a polymerase activation step at $94^{\circ} \mathrm{C}$ for $10 \mathrm{~min}$ followed by $94^{\circ} \mathrm{C}$ for $10 \mathrm{~s}, 60^{\circ} \mathrm{C}$ for $20 \mathrm{~s}$, and $72^{\circ} \mathrm{C}$ for $25 \mathrm{~s}$.

\section{Western blotting}

Total protein was extracted as previously described. Briefly, the cultured cells were lysed with cell lysis buffer $(50 \mathrm{mM}$ Tris- $\mathrm{HCl}, \mathrm{pH} 8.0,150 \mathrm{mM} \mathrm{NaCl}, 1 \%$ TritonX-100). Then the homogenate was centrifuged and the supernatant was collected for western blotting. Supernatant was separated by sodium dodecyl sulfate-polyacrylamide gel electrophoresis (SDS-PAGE) and transferred onto a nitrocellulose membrane (Millipore, Billerica, MA, USA). The blot was then probed with a primary antibody (rabbit anti-rat p-GluN1, sigma, American), followed by a horseradish peroxidase-conjugated secondary antibody (goat anti-rabbit p-GluN1, Sigma). The signal was detected using enhanced chemiluminescence and recorded on X-ray film.

\section{Statistical Analysis}

All results are reported as means \pm SE. Statistical significance was determined using SPSS 11.0 for Windows. One-way analysis of variance (ANOVA) was performed for multiple comparisons, followed by Fisher's least standard difference (LSD) post-hoc comparison. Differences were deemed statistically significant for $\mathrm{P}<0.05$. 


\section{RESULTS}

\section{Effects of remifentanil (with or without ketamine or naloxone) on DHN GluN1 mRNA levels by real-time RT-PCR analysis}

We first examined the effect of remifentanil on the mRNA levels of the GluN1 subunit of the NMDAR by real time RT-PCR. The results showed that the GluN1 mRNA levels in DHNs increased significantly after remifentanil treatment in Group R compared with the control Group C $(\mathrm{P}<0.05)$. The effect of remifentanil increased with time. The mRNA levels increased at $1 \mathrm{~h}$ and remained elevated for $24 \mathrm{~h}$. When ketamine was co-applied with remifentanil to DHNs in Group RK, the expression of mRNA was significantly lower compared with Group R $(\mathrm{P}<0.05)$. However, GluN1 mRNA levels in Group RK were still higher than in Group C, demonstrating that the effect of remifentanil was weakened but not completely prevented by ketamine. When naloxone was co-applied with remifentanil in Group RN, it also decreased GluN1 mRNA expression compared with Group R after $1 \mathrm{~h}$, although the magnitude of its suppression was significantly smaller than for ketamine. GluN1 mRNA levels in Group RN were higher than in Group R at $2 \mathrm{~h}$, but naloxone decreased GluN1 mRNA levels significantly at 4 and $24 \mathrm{~h}(\mathrm{P}<0.05)$. This effect was most pronounced at $24 \mathrm{~h}$; however, GluN1 mRNA levels were still higher than they were in Group RK (Figure 1).

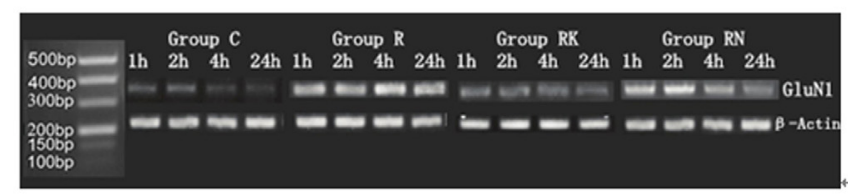

A

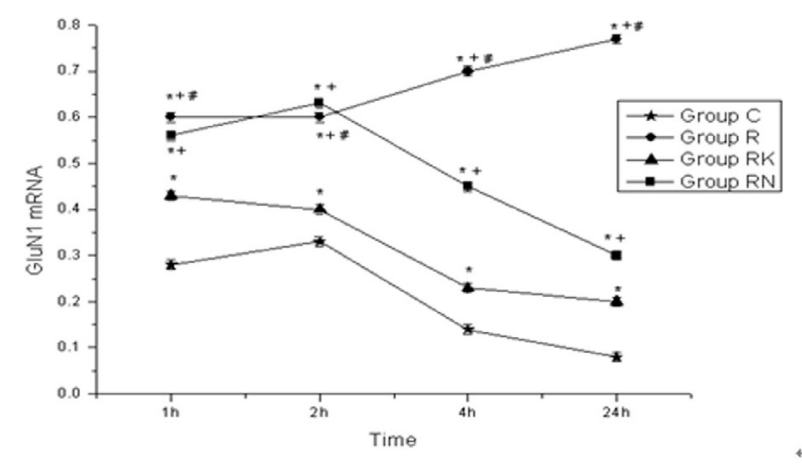

B

Figure 1. A. Image of agarose gel electrophoresis of the PCR product. B. Relative GluN1 mRNA levels normalized with actin. Each point represents the mean $\pm S E$ of three independent experiments $(N=3)$. Circles represent Group R treated with $4 \mathrm{nM}$ remifentanil. Triangles represent Group RK treated with $4 \mathrm{nM}$ remifentanil and 100 $\mu \mathrm{M}$ ketamine. Squares represent Group RN treated with $4 \mathrm{nM}$ remifentanil and $100 \mathrm{nM}$ naloxone. Pentagrams represent Group C (control). Remifentanil significantly increased GluN1 mRNA levels in a time-dependent and persistent manner. Ketamine and naloxone partially inhibited the effect of remifentanil, but the inhibition effect of ketamine was greater than naloxone. ${ }^{*} \mathrm{P}<0.05$ vs Group $\mathrm{C},{ }^{+} \mathrm{P}<0.05$ vs Group $\mathrm{RK},{ }^{*} \mathrm{P}<0.05$ vs Group RN. Oneway ANOVA was used to analyze the data. 


\section{Effects of remifentanil (with or without ketamine or naloxone) on DHN p-GluN1 protein levels}

To quantify the expression of $\mathrm{p}-\mathrm{GluN} 1$ protein in DHNs during remifentanil-induced hyperalgesia, western blot studies were performed. As seen with GluN1 mRNA levels, remifentanil treatment induced a persistent increase of $\mathrm{p}-\mathrm{GluN1}$ protein levels $(\mathrm{P}<0.05)$. The $\mathrm{p}$ GluN1 increase was partially inhibited in Group RK and Group RN compared with Group R, implying that ketamine and naloxone prevent the increased phosphorylation of GluN1 directly induced by remifentanil $(\mathrm{P}<0.05)$. Furthermore, the effect of ketamine was greater than that of naloxone, as seen with the changes in GluN1 mRNA levels (Figure 2).
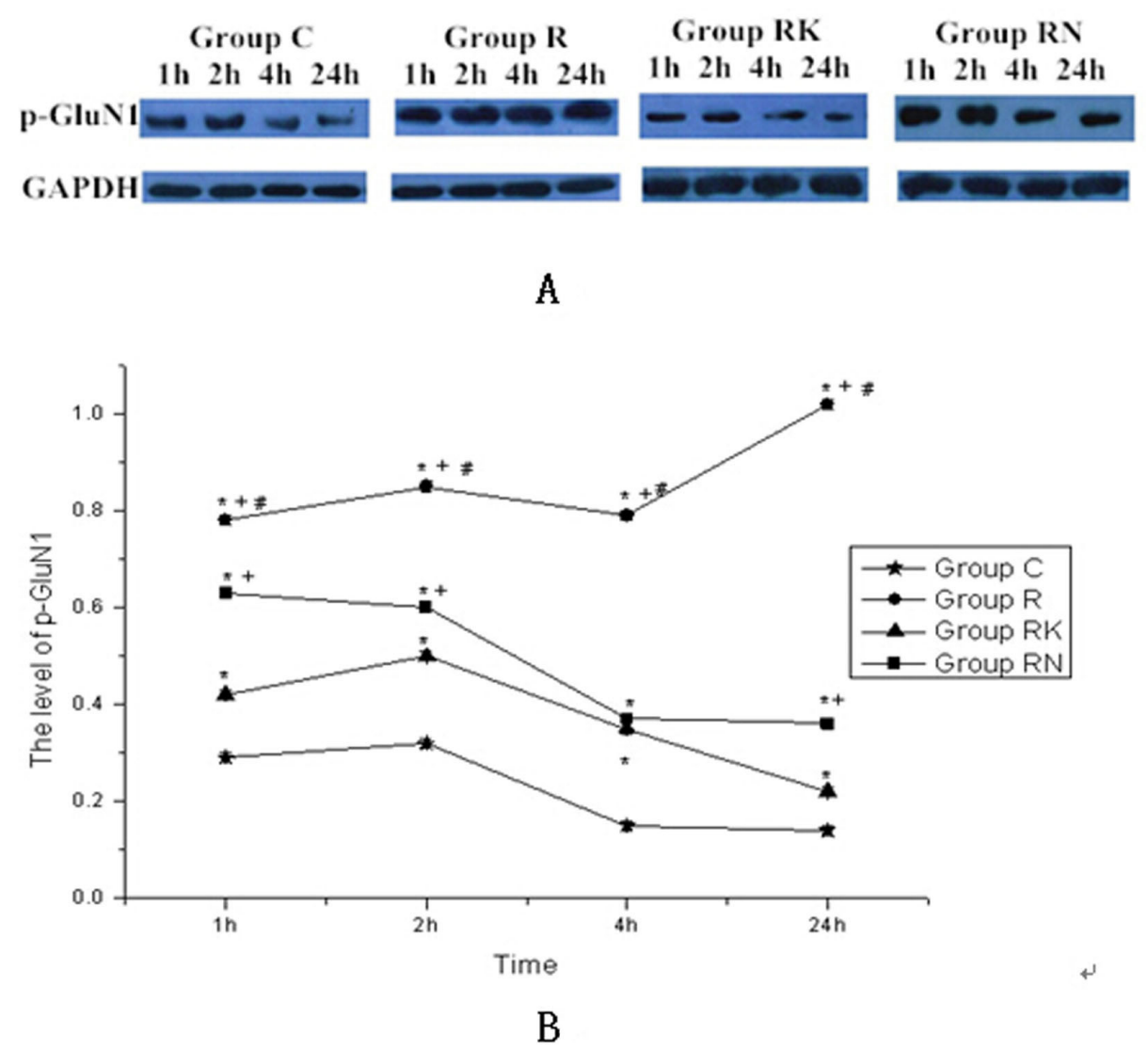

Figure 2. A. Representative image of western blot bands. B. Relative p-GluN1 protein levels normalized with GAPDH. Each point represents the mean \pm SE of three independent experiments $(N=3)$. Circles represent Group $\mathrm{R}$ with $4 \mathrm{nM}$ remifentanil. Triangles represent Group RK with $4 \mathrm{nM}$ remifentanil and $100 \mu \mathrm{M}$ ketamine. Squares represent Group RN with $4 \mathrm{nM}$ remifentanil and $100 \mathrm{Nm}$ naloxone. Pentagrams represent Group C (control). Total protein was isolated and western blot was performed to determine p-GluN1 protein levels. As seen with GluN1 mRNA levels, remifentanil treatment induced a time-dependent increase of $\mathrm{p}-\mathrm{GluN1}$ protein levels $(\mathrm{P}<0.05)$. The increased in p-GluN1 was partially inhibited in Group RK and Group RN compared with Group R, indicating that ketamine and naloxone weakened the effect of remifentanil on p-GluN1 levels. ${ }^{*} \mathrm{P}<0.05$ ss Group $\mathrm{C},{ }^{+} \mathrm{P}<0.05$ vs Group RK, ${ }^{*} \mathrm{P}<0.05$ vs Group RN. One-way ANOVA was used to analyze the data. 


\section{DISCUSSION}

In this study, we chose primary cultures of embryonic rat DHNs as a model to study the mechanisms of remifentanil-induced acute opioid tolerance and hyperalgesia. Our results demonstrated that remifentanil treatment significantly elevated the expression of GluN1 mRNA and p-GluN1 protein levels, indicating the upregulation of NMDARs may be involved in acute opioid tolerance and hyperalgesia after remifentanil administration.

What is the relationship between the NMDAR and the $\mu$-opioid receptor? An increasing number of both anatomical and physiological studies have found that these receptors are closely linked. One study has found that the HINT1 protein that binds to the C-terminus of $\mu$-opioid receptors is required to enhance the function of NMDARs (Rodríguez-Muñoz et al., 2011). In the absence of stimulation, NMDARs are linked with $\mu$-opioid receptors through HINT1. However, when these receptors are exposed to $\mu$-opioid receptor agonists, such as remifentanil, this connection can be broken. This causes an increase in the sensitivity of NMDARs to glutamate and glycine, leading to membrane depolarization (Ikeda et al., 2006). The activated NMDARs then allow $\mathrm{Ca}^{2+}$ to enter into neurons. This rapid increase in intracellular $\mathrm{Ca}^{2+}$ is the initial trigger for activity-dependent synaptic plasticity. When intracellular $\mathrm{Ca}^{2+}$ is increased beyond a certain level, multiple intracellular signaling pathways, including protein kinase A and C (PKA, PKC), and Src family kinases (SFKs) are activated. Subsequently, NMDAR function is enhanced through serine-threonine or tyrosine phosphorylation (Larsson, 2009; Latremoliere and Woolf, 2009; Larsson and Broman, 2011), leading to the propagation of the pain signal from neuron to neuron resulting in OIH.

In the current study, we measured the levels of GluN1 mRNA and p-GluN1 protein after a 1-h application of remifentanil (covering most clinical anesthetic times) by RT-PCR and western blot. The results demonstrate that exposure to remifentanil significantly increases the levels of GluN1 mRNA and p-GluN1 protein, and that the magnitude of this enhancement increases with time. This increase begins at $1 \mathrm{~h}$ and lasts for $24 \mathrm{~h}$, which explains why OIH induced by short-acting $\mu$-opioid receptor agonists in patients is very intense and long lasting. Furthermore, our results suggest that the molecular basis for this phenomenon may be the phosphorylation of GluN1 and induction of additional intracellular signaling cascades.

Ketamine, a noncompetitive NMDAR antagonist, is a widely used general anesthetic. Although ketamine acts on a variety of receptors, the analgesic effect of ketamine mainly stems from its antagonism of NMDARs and prevention of central sensitization. Wang et al. (2006) found that $10 \mu \mathrm{M}$ ketamine administered to macaques three days after birth increases the expression of GluN1 in neurons within the frontal cortex. In our study of Group RK, which received ketamine and remifentanil treatment, ketamine inhibited the effects of remifentanil, although GluN1 mRNA levels were still higher than in the controls. This suggests that the effect of remifentanil can be weakened, but not completely prevented, by ketamine.

In a study from Lin et al. (2010), attenuation of glutamatergic transmission and neuroinflammation by ultra-low dose naloxone co-infusion preserved the lasting antinociceptive effect of morphine in rats chronically infused with morphine. In a second study, the same group also demonstrated that ultra-low dose naloxone enhanced the antinociceptive effect of morphine in partial sciatic nerve-transected rats (Yang et al., 2011). Our results support these findings in that ketamine and naloxone dampened the remifentanil-induced increase in GluN1 mRNA levels and p-GluN1 protein; however, the effect with naloxone was weaker than with ketamine. 
In conclusion, our study provides evidence for interactions between $\mu$-opioid receptors and NMDARs, and demonstrates that remifentanil induces an increase in GluN1 mRNA and protein levels in primary rat DHNs, which may partially account for remifentanil-induced hyperalgesia. However, the mechanisms underlying the upregulation of NMDARs have not been clearly elucidated and should be further studied in future experiments. Importantly, this upregulation can be partially prevented by ketamine and naloxone, which holds potential therapeutic value for the prevention of $\mathrm{OIH}$.

\section{Conflicts of interest}

The authors declare no conflict of interests.

\section{ACKNOWLEDGMENTS}

Research supported by the Grant of Health Bureau research projects (\#2013-1-031), the Science \& Technology Commission (\#cstc2014jcyjA10038, \#cstc2014yykfB10010), and the Program for Innovation Team Building at Institutions of Higher Education in Chongqing (2013).

\section{REFERENCES}

Angst MS and Clark JD (2006). Opioid-induced Hyperalgesia: A Qualitative Systematic Review. Anesthesiology 104: 570-587.

Celerier E, Laulin J, Larcher A, Le Moal M, et al. (1999). Evidence for opiate-activated NMDA processes masking opiate analgesia in rats. Brain Res. 847: 18-25.

Colvin LA and Fallon MT (2010). Opioid-induced hyperalgesia: a clinical challenge. Br. J. Anaesth. 104: 125-127.

Derrode N, Lebrun F, Levron JC, Chauvin M, et al. (2003). Influence of perioperative opioid on postoperative pain after major abdominal surgery: Sufentanil TCI versus remifentanil TCI. A randomized, controlled study. Br. J. Anaesth. 91: 842-849.

Du J, Zhou S, Coggeshall RE and Carlton SM. (2003). N-methyl-D-aspartate-induced excitation and sensitization of normal and inflamed nociceptors. Neuroscience 118: 547-562.

Furukawa H, Singh SK, Mancusso R and Gouaux E (2005). Subunit arrangement and function in NMDA receptors. Nature 438: 185-192.

Gu X, Wu X, Liu Y, Cui S, et al. (2009). Tyrosine phosphorylation of the N-Methyl-D-Aspartate receptor 2B subunit in spinal cord contributes to remifentanil-induced postoperative hyperalgesia: the preventive effect of ketamine. Mol. Pain 5: 76-84.

Guignard B, Bossard AE, Coste C, Sessler DI, et al. (2000). Acute opioid tolerance: intraoperative remifentanil increases postoperative pain and morphine requirement. Anesthesiology 93: 409-417.

Guntz E, Dumont H, Roussel C, Gall D, et al. (2005). Effects of remifentanil on N-methyl-D-aspartate receptor: An electrophysiologic study in rat spinal cord. Anesthesiology 102: 1235-1241.

Hahnenkamp K, Nollet J, Van Aken HK, Buerkle H, et al. (2004). Remifentanil directly activates human N-methyl-Daspartate receptors expressed in Xenopus laevis oocytes. Anesthesiology 100: 1531-1537.

Hang LH, Shao DH and Gu YP (2011). The ED50 and ED95 of ketamine for prevention of postoperative hyperalgesia after remifentanil-based anaesthesia in patients undergoing laparoscopic cholecystectomy. Swiss Med. Wkly 141: w13195-13199.

Hirota K and Lambert DG (1996). Ketamine: Its mechanism(s) of action and unusual clinical uses. Br. J. Anaesth. 77: 441-444.

Hood DD, Curry R and Eisenach JC (2003). Intravenous remifentanil produces withdrawal hyperalgesia in volunteers with capsaicin-induced hyperalgesia. Anesth. Analg. 97: 810-815.

Ikeda H, Stark J, Fischer H, Wagner M, et al. (2006). Synaptic amplifier of inflammatory pain in the spinal dorsal horn. Science 312: 1659-1662.

Larsson M (2009). Ionotropic glutamate receptors in spinal nociceptive processing. Mol. Neurobiol. 40: 260-288.

Larsson M and Broman J (2011). Synaptic plasticity and pain: role of ionotropic glutamate receptors. Neuroscientist 17 : 256-273. 
Latremoliere A and Woolf CJ (2009). Central sensitization: a generator of pain hypersensitivity by central neural plasticity. J. Pain 10: 895-926.

Lau CG and Zukin RS (2007). NMDA receptor trafficking in synaptic plasticity and neuropsychiatric disorders. Nat. Rev. Neurosci. 8: 413-426.

Li X, Angst MS and Clark JD (2001). Opioid-induced hyperalgesia and incisional pain. Anesth. Analg. 93: 204-209.

Lin SL, Tsai RY, Shen CH, Lin FH, et al. (2010). Co-administration of ultra-low dose naloxone attenuates morphine tolerance in rats via attenuation of NMDA receptor neurotransmission and suppression of neuroinflammation in the spinal cords. Pharmacol. Biochem. Behav. 96: 236-245.

Minville V, Fourcade O, Girolami JP and Tack I. (2010). Opioid-induced hyperalgesia in a mice model of orthopaedic pain: preventive effect of ketamine. Br. J. Anaesth. 104: 231-238.

Nagy GG, Watanabe M, Fukaya M and Todd AJ. (2004). Synaptic distribution of the NR1, NR2A and NR2B subunits of the $\mathrm{N}$-methyld-aspartate receptor in the rat lumbar spinal cord revealed with an antigenunmasking technique. Eur. $J$. Neurosci. 20: 3301-3312.

Nong Y, Huang YQ, Ju W, Kalia LV, et al. (2003). Glycine binding primes NMDA receptor internalization. Nature 422: 302-307.

Paoletti P and Neyton J (2007). NMDA receptor subunits: function and pharmacology. Curr. Opin. Pharmacol. 7: 39-47.

Rodríguez-Muñoz M, Torre-Madrid E, Sánchez-Blázquez P and Garzón J. (2011). NO-released zinc supports the simultaneous binding of Raf-1 and $\mathrm{KC} \gamma$ cysteine-rich domains to HINT1 protein at the mu-opioid receptor. Antioxid. Redox. Signal. 14: 2413-2425.

Tsai RY, Jang FL, Tai YH, Lin SL, et al. (2008). Ultra-low-dose naloxone restores the antinociceptive effect of morphine and suppresses spinal neuroinflammation in PTX-treated rats. Neuropsychopharmacology 33: 2772-2782.

Wang C, Sadovova N and Hotchkiss C (2006). Blockade of N-methyl-D-aspartate receptors by ketamine produces loss of postnatal day 3 monkey frontal cortical neurons in culture. Toxicol. Sci. 91: 192-201.

Yang CP, Cherng CH, Wu CT, Huang HY, et al. (2011). Intrathecal ultra-low dose naloxone enhances the antinociceptive effect of morphine by enhancing the reuptake of excitatory amino acids from the synaptic cleft in the spinal cord of partial sciatic nerve-transected rats. Anesth. Analg. 113: 1490-1500.

Zhao M and Joo DT (2008). Enhancement of spinal N-methyl-D-aspartate receptor function by remifentanil action at deltaopioid receptors as a mechanism for acute opioid-induced hyperalgesia or tolerance. Anesthesiology 109: 308-317. 